\title{
Arsenic Metabolites and Methylation Capacity Among Individuals Living in a Rural Area with Endemic Arseniasis in Inner Mongolia, China
}

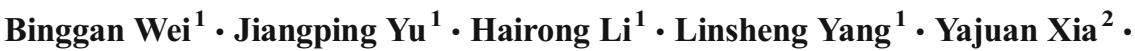

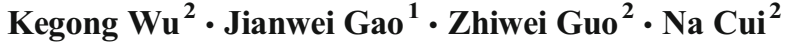

Received: 12 May 2015 / Accepted: 20 August 2015 / Published online: 3 September 2015

(C) Springer Science+Business Media New York 2015

\begin{abstract}
More than 0.3 million individuals are subject to chronic exposure to arsenic via their drinking water in Inner Mongolia, China. To determine arsenic methylation capacity profiles for such individuals, concentrations of urinary arsenic metabolites were measured for 548 subjects using high-performance liquid chromatography and a hydride generator combined with inductively coupled plasma-mass spectrometry. Mean urinary concentrations of dimethylarsonic acid (DMA), monomethylarsonic acid (MMA), inorganic arsenic (iAs), and total arsenic (TAs) were $200.50,46.71,52.96$, and $300.17 \mu \mathrm{g} / \mathrm{L}$, respectively. The $\%$ iAs, \%DMA, and \%MMA were 15.98, 69.72, and $14.29 \%$. Mean urinary \%iAs and \%MMA were higher in males, while urinary \%DMA was higher in females. There was a strong positive correlation between \%iAs and $\%$ MMA, with negative correlations between \%iAs and $\% \mathrm{DMA}$, and \%iAs and \%MMA. In addition, \%iAs and \%MMA were positively associated with total arsenic in drinking water (WAs), while \%DMA was negatively related with WAs. Regression analysis indicated that the primary methylation index (PMI) and secondary methylation index (SMI) generally decreased with increasing WAs. Females had a
\end{abstract}

Linsheng Yang

yangls@igsnrr.ac.cn

Binggan Wei

weibg@igsnrr.ac.cn

1 Key Laboratory of Land Surface Pattern and Simulation, Institute of Geographical Sciences and Natural Resources Research, Chinese Academy of Sciences, 11 A Datun Road, Beijing 100101, People's Republic of China

2 Inner Mongolia Center for Endemic Disease Control and Research, Huhhot, Inner Mongolia, China higher arsenic methylation capacity compared to males. Younger subjects had lower primary arsenic methylation capacity. However, the secondary arsenic methylation capacity was hardly affected by age. Moreover, both primary and secondary arsenic methylation capacities were negatively related to WAs.

Keywords Arsenic · Methylation capacity · Arsenic metabolites $\cdot$ Drinking water

\section{Introduction}

Millions of people throughout the world suffer from chronic exposure to arsenic via their drinking water [1]. Even moderately elevated concentrations of inorganic arsenic (iAs) in drinking water pose a serious public health problem [2]. Previous epidemiological studies of individuals exposed to high arsenic levels in drinking water suggest that chronic arsenic exposure via drinking water is widely associated with a higher risk of skin lesions, hypertension, diabetes, cardiovascular diseases, and cancer of the skin, lungs, bladder, liver, and possibly kidneys [2-12]. Therefore, the World Health Organization guideline for arsenic in drinking water is $10 \mu \mathrm{g} / \mathrm{L}$ [13].

Arsenic in drinking water is dominated by iAs as pentavalent $\left(\mathrm{As}^{\mathrm{V}}\right)$ and trivalent arsenite $\left(\mathrm{As}{ }^{\mathrm{III}}\right)[14,15]$. In humans, the primary iAs metabolic pathway is methylation, which involves reduction and oxidative methylation [16-18]. After its ingestion in drinking water, iAs is readily absorbed by the gastrointestinal tract and methylated via oxidation to monomethylarsonic acid (MMA) in a process termed primary arsenic methylation. MMA can be further methylated to dimethylarsonic acid (DMA) in secondary arsenic methylation $[12,19]$. Arsenic species differ in their toxicity, and iAs 
is more toxic than organic arsenic. Therefore, arsenic methylation has been considered a detoxification mechanism because of the relatively low toxicity of MMA and DMA [20-23]. However, recent investigations suggest that $\mathrm{MMA}^{\mathrm{III}}$ and $\mathrm{DMA}^{\mathrm{III}}$ are more toxic than iAs arsenite [24, 25].

Urinary arsenic speciation is typically used as an indicator of arsenic metabolism in evaluating arsenic methylation capacity [26] in terms of the primary methylation index (PMI, defined as (MMA+DMA)/total arsenic (TAs)) and secondary methylation index (SMI, defined as DMA/(MMA+DMA)) [20, 27]. Numerous epidemiological studies have revealed that the risk of adverse health effects is associated with arsenic methylation capacity. A high percentage of MMA (\%MMA) in urine is positively related to cancer risk $[28,29]$. Kile et al. [1] reported that a higher proportion of MMA in urine was correlated with a greater risk of skin lesions. Lindberg et al. [26] and Li et al. [30] confirmed that a higher proportion of MMA and a lower proportion of DMA in urine indicated a higher risk of arsenic-related skin lesions. Moreover, exposure of individuals with a low arsenic methylation capacity to high arsenic levels might confer a higher risk of carotid atherosclerosis [31]. Inefficient arsenic methylation and higher urinary MMA might be related to hypertension risk $[10,18]$. Chen et al. [15] suggested that incomplete methylation of arsenic is associated with a higher risk of heart disease. Several other studies showed positive correlations between the \%MMA in urine and the prevalence of arsenic-related toxic effects [32-34].

Urinary arsenic metabolite concentrations and arsenic methylation capacity are significantly associated with human health effects. Therefore, we measured urinary arsenic metabolites for 548 residents of a rural area in Inner Mongolia where tube well water is widely contaminated with arsenic. The aim of the study was to estimate concentrations and percentages of arsenic metabolites in urine. The arsenic methylation capacity of the study subjects was assessed, and factors affecting arsenic methylation capacity were analyzed.

\section{Materials and Methods}

\section{Study Area and Subjects}

The study area, the Bameng region, is located north of the Yellow River in western Inner Mongolia, People's Republic of China. The groundwater in this area typically contains high arsenic concentrations of up to $1354 \mu \mathrm{g} / \mathrm{L}[35,36]$. Residents typically use high-arsenic groundwater for drinking water.

Individuals who had ingested seafood in the previous week, pregnant women, and children younger than 10 years were excluded from the study cohort. Consequently, 548 residents (389 females and 159 males) living in eight villages were selected for the study. All the subjects signed informed consent forms agreeing to participation in the study before specimen collection and interview. The interview questionnaire collected data on gender, age, living conditions, dietary habits, smoking, alcohol consumption, and illness for all the subjects. The average age was 37.8 years (range 10-65) for females and 36.2 years (range 12-61) for males. Table 1 lists demographic data for the subjects. Among the male participants, approximately $64.15 \%$ smoked and $35.85 \%$ consumed alcohol. The corresponding rates for female participants were 12.85 and $1.29 \%$.

\section{Sample Collection}

Tube well water was pumped for approximately $5 \mathrm{~min}$ to remove water at the tip of the tap before samples were collected. Approximately $100 \mathrm{~mL}$ of water was collected into a clean polyethylene bottle for each sample. Samples were stored at $-20{ }^{\circ} \mathrm{C}$.

Approximately $50 \mathrm{~mL}$ of first-morning-void urine was collected in a $100-\mathrm{mL}$ polypropylene tube for each subject. Urine samples were immediately placed on ice and transferred to the Inner Mongolia Center for Endemic Disease Control and Research in Hohhot within $8 \mathrm{~h}$, where they were stored at $-20{ }^{\circ} \mathrm{C}$.

Urine and water samples were kept on dry ice and transported to the laboratory for arsenic analysis in the Institute of Geographic Sciences and Natural Resources Research (Beijing, China) and stored in a low-temperature refrigerator until analysis. Collection of urine and water samples was completed before a water improvement program was initiated in the study area.

\section{Determination of Urinary Arsenic Species}

To investigate arsenic metabolism and methylation profiles for individuals exposed to high levels of arsenic in drinking water, urinary arsenic metabolites were separated on a highperformance liquid chromatography (HPLC) system equipped with a hydride generator [30, 37]. Concentrations of iAs (including $\mathrm{As}^{\mathrm{III}}$ and $\mathrm{As}^{\mathrm{V}}$ ), MMA, and DMA in urine samples were determined by inductively coupled plasma-mass spectrometry (ICP-MS). TAs concentrations in water samples were determined by HPLC and ICP-MS after filtration through $0.45-\mu \mathrm{m}$ membranes. The detection limit of this method for As species was $1 \mathrm{ng}$. A standard reference material containing $1000 \mathrm{mg} / \mathrm{L}$ iAs, MMA, and DMA (National Center for Standard Reference Materials) was used to check the validity of urinary arsenic species measurement. The reliability of the arsenic species determination was evaluated in terms of the analytical recovery rate for added arsenic species. The 
Table 1 The demographic characteristics of study subjects

\begin{tabular}{lllllll}
\hline Item & $N$ & Min & Max & Mean & Smoking (\%) & Alcohol consumption (\%) \\
\hline Total & 548 & 10 & 65 & 37.3 & 21.74 & 11.31 \\
Female & 389 & 10 & 65 & 37.8 & 12.85 & 1.29 \\
Male & 159 & 12 & 61 & 36.2 & 64.15 & 35.85 \\
\hline
\end{tabular}

recovery rate was $83-94 \%$ for iAs, $91-97 \%$ for MMA, and $90-102 \%$ for DMA.

\section{Statistical Analysis}

The TAs concentration in urine was calculated as the sum of $\mathrm{iAs}+\mathrm{MMA}+\mathrm{DMA}$. Arsenic methylation indices were defined as the percentages of respective arsenic species in urine samples. Moreover, PMI was calculated as (MMA+DMA)/ TAs and SMI as DMA/(MMA+DMA) [27].

SPSS version 18.0 for Windows was used for descriptive statistics, regression analysis, and correlation analysis. Linear regression analysis was used to estimate correlations between TAs concentrations, percentage of arsenic metabolites in urine, and total arsenic content in drinking water (WAs). Pearson correlation coefficients were calculated. In addition, the Student's $t$ test was applied to evaluate differences in urinary arsenic metabolites between males and females. Differences in urinary arsenic metabolites among age groups and arsenic levels in water were analyzed by ANOVA.

\section{Results}

\section{Concentrations of Arsenic Metabolites in Urine}

Arsenic concentrations in drinking water ranged from 0.34 to $824.70 \mu \mathrm{g} / \mathrm{L}$. Results for arsenic metabolites in urine and PMI and SMI are listed in Table 2. For the total cohort, mean urinary DMA, MMA, iAs, and TAs concentrations were 200.50, 46.71, 52.96, and 300.17 $\mu \mathrm{g} / \mathrm{L}$, and \%iAs, \%DMA, and \%MMA were $15.98,69.72$, and $14.29 \%$, respectively. Arsenic methylation capacity was estimated using PMI and SMI, which had mean values of 0.84 and 0.83 , respectively. Mean urinary DMA, MMA, iAs, and TAs concentrations were generally higher for males than for females. Mean

Table 2 Statistical data of arsenic metabolites in urine and methylation capacity index in the subjects $(\mu \mathrm{g} / \mathrm{L})$

\begin{tabular}{|c|c|c|c|c|c|c|c|c|c|}
\hline & DMA & MMA & iAs & TAs & $\% \mathrm{iAs}$ & $\% \mathrm{DMA}$ & $\% \mathrm{MMA}$ & PMI & SMI \\
\hline \multicolumn{10}{|c|}{ Total $(N=548)$} \\
\hline Mean & 200.50 & 46.71 & 52.96 & 300.17 & 15.98 & 69.72 & 14.29 & 0.84 & 0.83 \\
\hline Median & 116.75 & 22.15 & 24.20 & 168.45 & 14.48 & 71.05 & 13.73 & 0.85 & 0.84 \\
\hline Min & 2.90 & 0.50 & 0.50 & 4.30 & 2.56 & 25.64 & 0.95 & 0.40 & 0.54 \\
\hline Max & 1430.40 & 450.80 & 516.90 & 2063.50 & 59.50 & 89.73 & 29.67 & 0.97 & 0.99 \\
\hline $\mathrm{SD}$ & 227.78 & 62.18 & 71.80 & 346.45 & 7.65 & 9.38 & 4.44 & 0.08 & 0.06 \\
\hline \multicolumn{10}{|c|}{ Female $(N=389)$} \\
\hline Mean & 193.81 & 40.51 & 45.83 & 280.14 & 14.77 & 71.61 & 13.62 & 0.85 & 0.84 \\
\hline Median & 105.50 & 19.70 & 21.20 & 149.40 & 13.27 & 72.74 & 13.21 & 0.87 & 0.85 \\
\hline SD & 224.09 & 52.79 & 64.32 & 326.82 & 7.18 & 8.69 & 4.16 & 0.07 & 0.05 \\
\hline Min & 2.90 & 0.50 & 0.50 & 4.30 & 2.56 & 25.64 & 0.95 & 0.40 & 0.60 \\
\hline Max & 1430.40 & 316.90 & 516.90 & 1936.60 & 59.50 & 89.73 & 26.11 & 0.97 & 0.99 \\
\hline \multicolumn{10}{|c|}{ Male $(N=159)$} \\
\hline Mean & 219.32 & 62.27 & 70.75 & 352.35 & 18.92 & 65.16 & 15.92 & 0.81 & 0.80 \\
\hline Median & 143.70 & 34.70 & 37.40 & 213.70 & 17.71 & 64.67 & 15.982 & 0.82 & 0.81 \\
\hline SD & 236.49 & 78.72 & 85.02 & 386.53 & 7.96 & 9.47 & 4.71 & 0.08 & 0.06 \\
\hline Min & 10.40 & 1.40 & 1.70 & 15.40 & 4.06 & 34.31 & 5.97 & 0.50 & 0.54 \\
\hline Max & 1191.10 & 450.80 & 421.60 & 2063.50 & 49.83 & 82.70 & 29.67 & 0.96 & 0.93 \\
\hline \multicolumn{10}{|c|}{ Student's $t$ test between female and male } \\
\hline$P$ & 0.234 & 0.002 & 0.001 & 0.039 & 0.000 & 0.000 & 0.000 & 0.000 & 0.000 \\
\hline
\end{tabular}

Min minimum, Max maximum, SD standard deviation 
urinary \%iAs and \%MMA were also higher for males, while urinary \%DMA was higher for females.

\section{Urinary Arsenic Metabolites by Age Group}

The urinary arsenic concentrations, percentages, and methylation capacity might vary among different age groups. Therefore, the subjects were divided into six groups according to their age: $<20,21-30,31-40,41-50,51-60$, and $>60$ years. Among females, the mean DMA, MMA, and TAs concentration in urine generally increased with age, while the mean iAs decreased (Table 3). The mean \%iAs in urine decreased significantly with increasing age for both males and females. By contrast, the mean \%DMA and \%MMA largely increased with age. In terms of the arsenic methylation capacity among females, PMI increased from 0.82 for those aged $<20$ years to 0.89 for those aged $>60$ years. However, SMI varied slightly among the age groups. The highest value (0.85) was observed for those aged 21-30 years. For males, the mean urinary DMA, MMA, and TAs concentrations increased with age, whereas the mean iAs decreased with increasing age.

Table 3 shows that mean DMA, MMA, iAs, and TAs concentrations in urine were much higher for females than for males for subjects aged $<20$ years. By contrast, mean concentrations of these arsenic metabolites in urine were lower for females than for males among the other age groups. Moreover, the mean urinary \%iAs and \%MMA were lower for females than for males and the mean \%DMA was significantly higher for females among all age groups. PMI and SMI were much higher for females than for males. The highest PMI values for both females and males ( 0.89 and 0.85$)$ were among subjects aged $>60$ years, while the lowest PMI values ( 0.82 and 0.78 ) were among those aged $<20$ years. The highest SMI values for females and males ( 0.85 and 0.81$)$ were in those aged 21-30 and $<20$ years.

\section{Urinary Arsenic Metabolite Levels in Relation to Arsenic Levels in Drinking Water}

Different levels of arsenic in drinking water might significantly affect arsenic metabolite profiles and arsenic methylation capacity among individuals. Therefore, the concentrations and percentages of arsenic metabolites were calculated. The results are listed in Table 4. WAs levels were categorized as $<10,10-50,50-100,100-150,150-200,200-250,250$ $300,300-350,350-400,400-450,450-500$, and $>500 \mu \mathrm{g} / \mathrm{L}$. In general, urinary DMA, MMA, iAs, and TAs concentrations significantly increased with WAs. Similarly, $\% \mathrm{iAs}$ and \%MMA increased with WAs. However, \%DMA decreased with increasing WAs (Table 4). Regression analysis results also indicate that \%iAs and \%MMA were positively associated with WAs, while \%DMA was negatively correlated

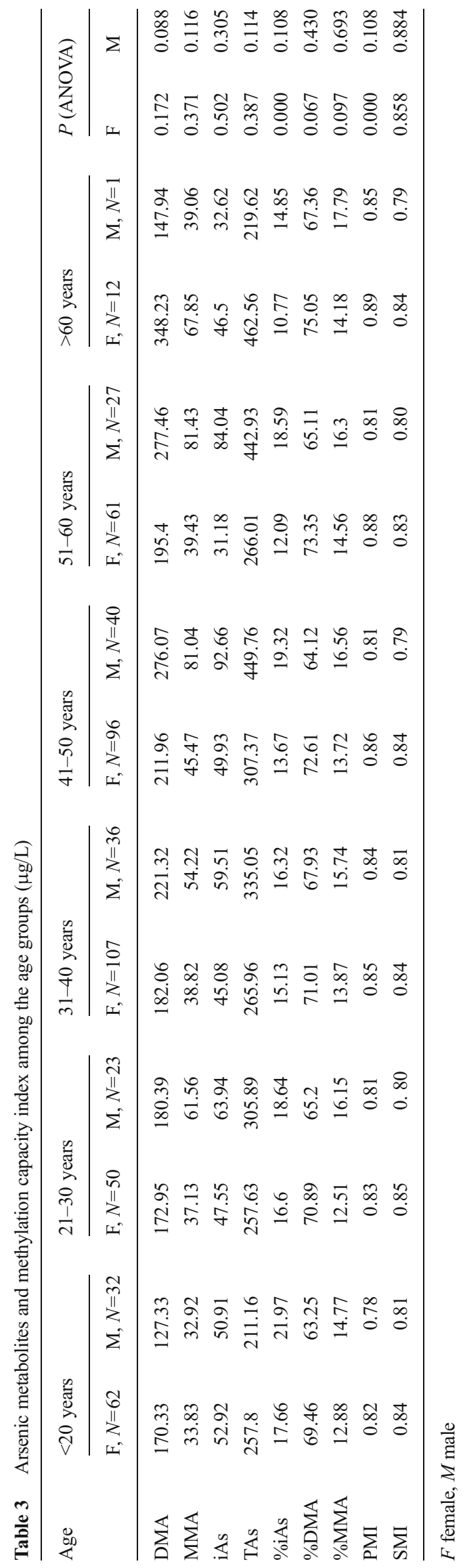


Table 4 Arsenic metabolites and methylation capacity index among different levels of arsenic in drinking water $(\mu \mathrm{g} / \mathrm{L})$

\begin{tabular}{|c|c|c|c|c|c|c|c|c|}
\hline & $N$ & DMA & MMA & iAs & TAs & $\% \mathrm{iAs}$ & $\% \mathrm{DMA}$ & $\%$ MMA \\
\hline \multicolumn{9}{|l|}{ Total } \\
\hline$<10$ & 103 & 37.76 & 7.19 & 9.03 & 53.98 & 14.05 & 73.46 & 12.49 \\
\hline $10-50$ & 89 & 60.96 & 11.58 & 11.75 & 84.30 & 14.16 & 72.24 & 13.60 \\
\hline $50-100$ & 64 & 112.74 & 21.27 & 19.78 & 153.79 & 13.23 & 73.18 & 13.59 \\
\hline $100-150$ & 45 & 143.58 & 31.00 & 35.21 & 209.81 & 16.46 & 68.65 & 14.89 \\
\hline $150-200$ & 60 & 192.81 & 43.25 & 43.88 & 279.93 & 15.83 & 69.12 & 15.06 \\
\hline $200-250$ & 32 & 280.46 & 61.23 & 65.35 & 407.04 & 15.88 & 68.99 & 15.13 \\
\hline $250-300$ & 39 & 306.42 & 69.77 & 82.35 & 458.55 & 17.72 & 67.69 & 14.58 \\
\hline $300-350$ & 34 & 405.07 & 98.23 & 112.22 & 615.53 & 18.34 & 65.77 & 15.88 \\
\hline $350-400$ & 23 & 527.51 & 129.17 & 147.75 & 804.41 & 17.45 & 66.97 & 15.57 \\
\hline $400-500$ & 25 & 447.67 & 114.63 & 127.44 & 689.75 & 20.73 & 63.12 & 16.16 \\
\hline$>500$ & 34 & 508.58 & 135.84 & 172.35 & 816.74 & 22.68 & 61.48 & 15.83 \\
\hline$P$ & & 0.000 & 0.000 & 0.000 & 0.000 & 0.000 & 0.000 & 0.000 \\
\hline \multicolumn{9}{|l|}{ Female } \\
\hline$<10$ & 72 & 35.92 & 6.53 & 7.28 & 49.74 & 12.34 & 75.38 & 12.28 \\
\hline $10-50$ & 74 & 61.69 & 11.14 & 11.15 & 83.99 & 13.53 & 73.30 & 13.17 \\
\hline $50-100$ & 50 & 112.15 & 20.04 & 18.91 & 151.10 & 13.16 & 73.56 & 13.28 \\
\hline $100-150$ & 29 & 146.87 & 30.92 & 32.81 & 210.61 & 15.55 & 69.43 & 15.02 \\
\hline $150-200$ & 36 & 196.58 & 36.79 & 40.26 & 273.62 & 14.75 & 71.83 & 13.43 \\
\hline $200-250$ & 21 & 268.89 & 52.66 & 61.24 & 382.78 & 15.29 & 70.65 & 14.05 \\
\hline $250-300$ & 28 & 302.02 & 61.34 & 73.29 & 436.65 & 16.48 & 70.16 & 13.34 \\
\hline $300-350$ & 24 & 415.38 & 90.41 & 98.13 & 603.92 & 16.91 & 68.40 & 14.69 \\
\hline $350-400$ & 16 & 470.74 & 102.86 & 119.24 & 692.83 & 16.15 & 68.70 & 15.14 \\
\hline $400-500$ & 17 & 493.22 & 110.66 & 105.92 & 709.81 & 16.31 & 68.27 & 15.42 \\
\hline$>500$ & 22 & 514.00 & 123.57 & 169.50 & 807.06 & 22.33 & 62.64 & 15.03 \\
\hline$P$ & & 0.000 & 0.000 & 0.000 & 0.000 & 0.000 & 0.000 & 0.020 \\
\hline \multicolumn{9}{|l|}{ Male } \\
\hline$<10$ & 31 & 42.03 & 8.74 & 13.09 & 63.84 & 18.02 & 69.02 & 12.96 \\
\hline $10-50$ & 15 & 59.90 & 14.41 & 15.39 & 89.72 & 17.41 & 66.82 & 15.77 \\
\hline $50-100$ & 14 & 114.87 & 25.66 & 22.87 & 163.42 & 13.49 & 71.83 & 14.68 \\
\hline $100-150$ & 16 & 137.64 & 31.16 & 39.55 & 208.38 & 18.10 & 67.24 & 14.66 \\
\hline $150-200$ & 24 & 187.16 & 52.93 & 49.32 & 289.40 & 17.45 & 65.05 & 17.50 \\
\hline $200-250$ & 11 & 302.55 & 77.60 & 73.18 & 453.35 & 16.98 & 65.82 & 17.20 \\
\hline $250-300$ & 28 & 317.62 & 91.24 & 105.42 & 514.28 & 20.88 & 61.41 & 17.71 \\
\hline $300-350$ & 11 & 380.31 & 117.00 & 146.03 & 643.39 & 21.79 & 59.47 & 18.74 \\
\hline $350-400$ & 7 & 657.26 & 189.29 & 212.91 & 1059.4 & 20.42 & 63.03 & 16.55 \\
\hline $400-500$ & 9 & 357.71 & 116.47 & 160.63 & 634.84 & 28.02 & 54.90 & 17.08 \\
\hline$>500$ & 12 & 498.63 & 158.32 & 177.58 & 834.48 & 23.33 & 59.36 & 17.31 \\
\hline$P$ & & 0.000 & 0.000 & 0.000 & 0.000 & 0.002 & 0.000 & 0.004 \\
\hline
\end{tabular}

to WAs (Fig. 1). The trends for urinary arsenic metabolites among females and males were similar to the trends for the entire cohort (Table 4).

\section{Correlations Among Urinary Arsenic Metabolites, PMI, and SMI}

Correlation coefficients for arsenic metabolites, PMI, SMI, and WAs are listed in Table 5. There are strong positive correlations between WAs and urinary DMA, MMA, iAs, and TAs. The \% iAs and \%MMA are significantly correlated with urinary concentrations of arsenic metabolites. There is a positive correlation between \% $\%$ As and $\%$ MMA and significantly negative correlations between $\%$ iAs and \%DMA, and \%MMA and \%DMA. In addition, $\%$ iAs and \%MMA are positively associated with WAs, while \%DMA is negatively associated with WAs. PMI and SMI are negatively correlated with urinary 

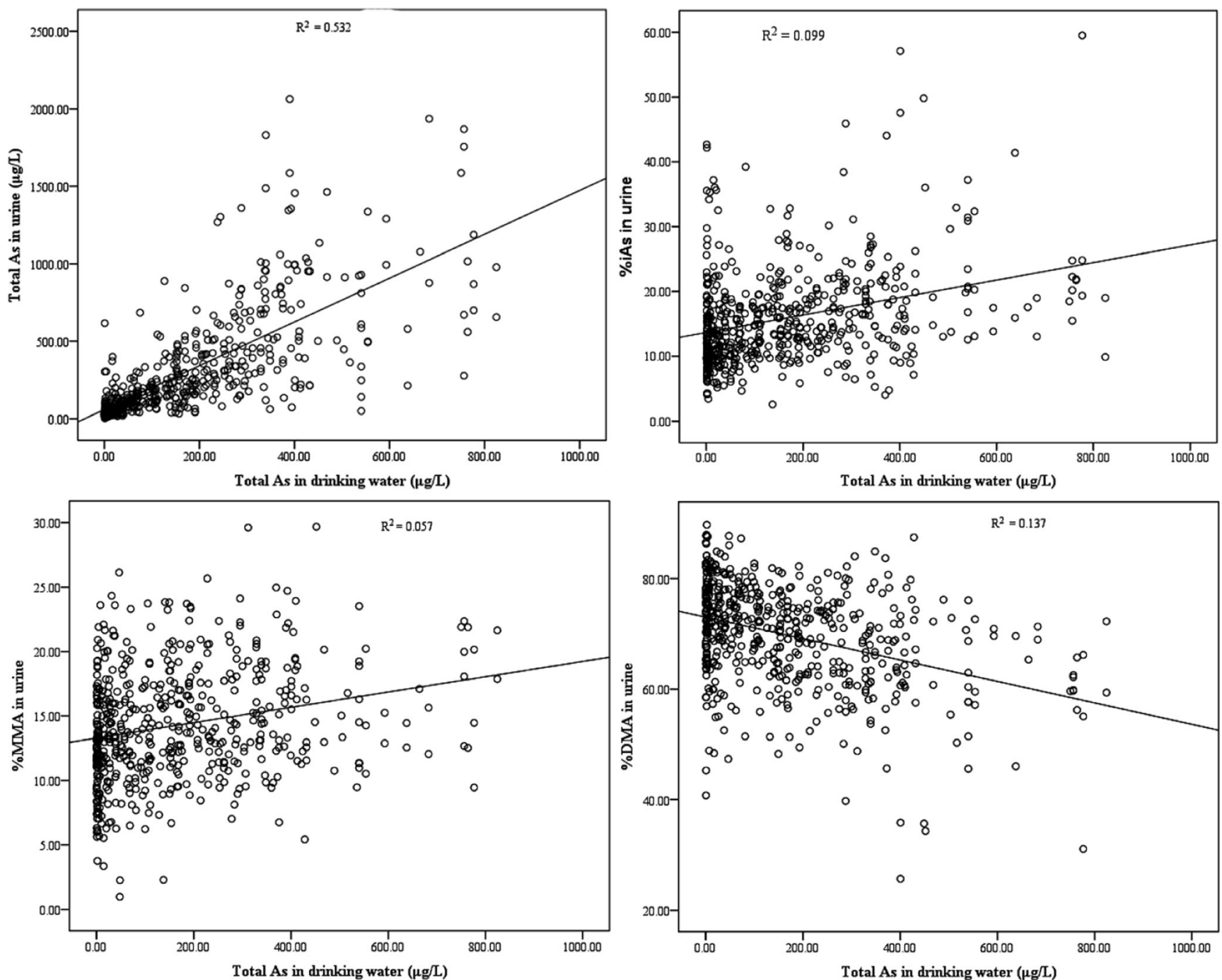

Fig. 1 Correlations between WAs and TAs and percentages of arsenic metabolites in urine

concentrations of arsenic metabolites, WAs, \%iAs, and \%MMA. However, PMI and SMI are positively correlated with \%DMA. Regression analysis results also indicate that
PMI and SMI decrease with increasing WAs (Fig. 2). Figure 3 shows that PMI and SMI for both females and male were negatively associated with WAs.

Table 5 Correlation coefficients among concentrations and percentages of arsenic metabolites in urine, PMI, SMI, and WAs

\begin{tabular}{|c|c|c|c|c|c|c|c|c|c|c|}
\hline & DMA & MMA & iAs & TAs & $\%$ iAs & $\% \mathrm{DMA}$ & $\% \mathrm{MMA}$ & PMI & SMI & WAs \\
\hline DMA & 1 & $0.898 * *$ & $0.793 * *$ & $0.983 * *$ & 0.079 & $-0.148 * *$ & $0.177 * *$ & -0.079 & $-0.178 * *$ & $0.698 * *$ \\
\hline MMA & & 1 & $0.867 * *$ & $0.949 * *$ & $0.200 * *$ & $-0.365^{* *}$ & $0.426^{* *}$ & $-0.200 * *$ & $-0.450 * *$ & $0.684 * *$ \\
\hline iAs & & & 1 & $0.884 * *$ & $0.485^{* *}$ & $-0.521 * *$ & $0.265^{* *}$ & $-0.485^{* *}$ & $-0.401 * *$ & $0.715^{* *}$ \\
\hline TAs & & & & 1 & $0.189 * *$ & $-0.271 * *$ & $0.247 * *$ & $-0.189 * *$ & $-0.281 * *$ & $0.730 * *$ \\
\hline$\%$ iAs & & & & & 1 & $-0.0883 * *$ & $0.144 * *$ & $-1.000 * *$ & $-0.442 * *$ & $0.315^{* *}$ \\
\hline$\% \mathrm{DMA}$ & & & & & & 1 & $-0.591 * *$ & $0.883 * *$ & $0.807 * *$ & $-0.370 * *$ \\
\hline$\% \mathrm{MMA}$ & & & & & & & 1 & $-0.144 * *$ & $-0.943 * *$ & $0.239 * *$ \\
\hline PMI & & & & & & & & 1 & $0.442 * *$ & $-0.315^{* *}$ \\
\hline SMI & & & & & & & & & 1 & $-0.315^{* *}$ \\
\hline WAs & & & & & & & & & & 1 \\
\hline
\end{tabular}

*Significant value $p \leq 0.05 ; * *$ significant value $p \leq 0.01$ 

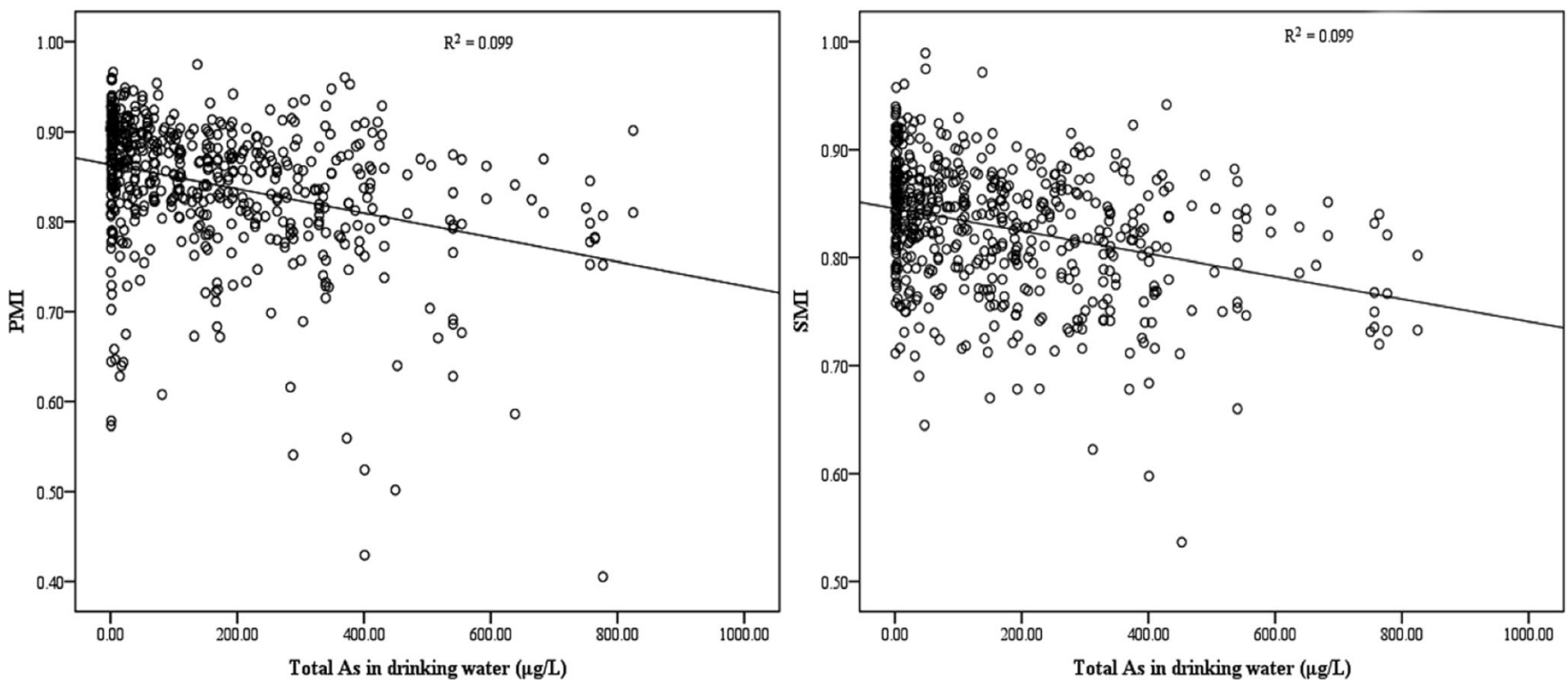

Fig. 2 Correlations between WAs and arsenic methylation capacity index of human

\section{Discussion}

Mean urinary concentrations of DMA, MMA, iAs, and TAs were higher among the study subjects than among subjects not exposed to high WAs levels $(>50 \mu \mathrm{g} / \mathrm{L})$. Saoudi et al. [38] reported that the geometric mean concentration of iAs + MMA + DMA was $3.75 \mu \mathrm{g} / \mathrm{L}$ for the adult population living in France [38]. Mean urinary concentrations of DMA, MMA, iAs, and TAs were also significantly higher in the total cohort than among subjects exposed to low WAs levels $(<10 \mu \mathrm{g} / \mathrm{L})$. Table 4 shows that mean urinary DMA, MMA, iAs, and TAs concentrations increased with the level of arsenic in drinking water ingested by subjects. Correlation analysis revealed significant positive correlations between WAs and arsenic metabolite concentrations in urine (Table 5), indicating a positive association between urinary arsenic metabolites and WAs. Agusa et al. $[39,40]$ reported that iAs concentrations in human urine are strongly dependent on iAs intake. Higher mean urinary DMA, MMA, iAs, and TAs concentrations among males suggest that the frequency of water ingestion might be higher for males than for females [39].

Percentages of arsenic metabolites in urine are typically used to provide insight into arsenic methylation capacity in humans $[21,41]$. A typical urinary arsenic metabolite profile contains $10-30 \%$ iAs, $10-20 \%$ MMA, and 60-80 \% DMA $[29,40,42]$. The urinary arsenic metabolite percentages observed for females and males in this study are consistent with previous studies. Higher urinary \%DMA and lower urinary
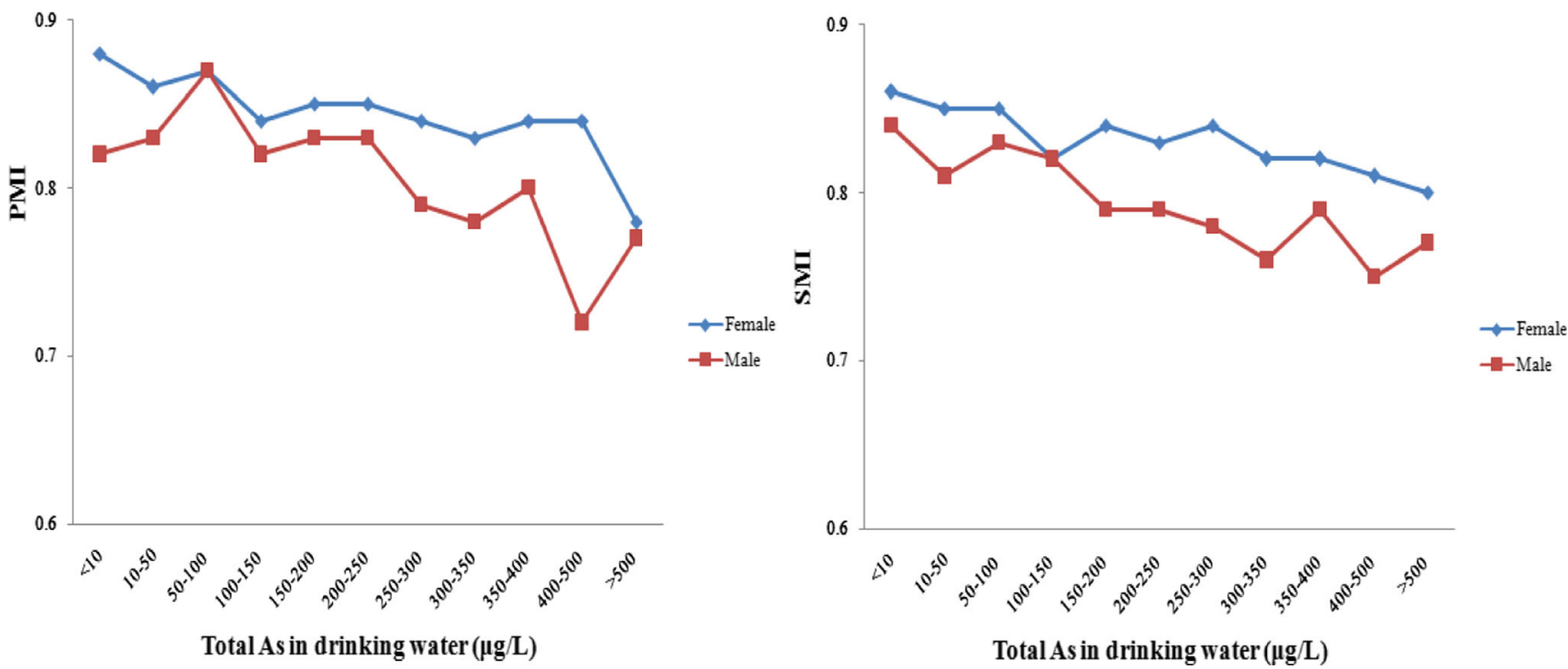

Fig. 3 The changes of PMI and SMI for both female and male with arsenic levels in drinking water 
\%iAs and \%MMA among females suggest that female metabolism may be influenced by sex steroids, resulting in more efficient arsenic methylation compared to males, in agreement with previous studies [30,43]. Previous investigations revealed that younger individuals had more efficient arsenic methylation [21]. However, the lower \%iAs and higher $\% \mathrm{DMA}$ and \%MMA observed for older groups in our study imply that older individuals had a higher arsenic methylation capacity than younger subjects. This might be because arsenic exposure influenced age-dependent urinary excretion of arsenic and methylation capacity [22]. A series of studies suggested that a higher proportion of MMA in urine might indicate retention of high-toxicity $\mathrm{MMA}^{\mathrm{III}}$ in body tissues and increase the risk of arsenic-related health effects [6, 44, 45]. Our results suggest that iAs might be excreted more quickly by younger people than by older individuals.

Exposure to different levels of arsenic in drinking water might affect the percentage of urinary arsenic metabolites. We found that higher WAs levels obviously increased urinary $\%$ iAs and \%MMA and decreased \%DMA (Table 4). Strong positive correlations between WAs and urinary \%iAs and $\%$ MMA and negative correlations between WAs and \%DMA confirm that arsenic levels in drinking water significantly affected iAs transformation to organic arsenic and arsenic methylation capacity. Previous studies also revealed that arsenic exposure levels negatively influence iAs metabolism [46].

PMI and SMI are typically used to estimate human arsenic methylation capacity [47]. In our study, PMI and SMI were generally higher among females than among males, indicating that females from the study area had a higher arsenic methylation capacity. This is consistent with previous investigations $[45,46]$. Several studies have revealed that the arsenic methylation capacity is widely influenced by age [12]. In our study, PMI clearly increased with age among females. Among males, PMI also increased with age up to 40 years. This suggests that older subjects have a higher primary arsenic methylation capacity. However, SMI varied slightly among the age groups for both females and males, indicating that the secondary arsenic methylation capacity of subjects might be not associated with age. These results differ from those of previous studies. Zhang et al. [12] reported that older people had a lower arsenic methylation capacity (lower \%DMA and SMI).

The study subjects were exposed to different levels of arsenic in their drinking water and thus ingested different doses of arsenic. Significantly negative correlations between arsenic levels in drinking water and PMI and SMI for the whole cohort and for both females and males confirm that human primary and secondary arsenic methylation capacities are both significantly negatively affected by high arsenic levels in drinking water. In addition, higher PMI and SMI in females suggest that females have higher primary and secondary arsenic methylation capacities compared to males. Other studies have also revealed that higher arsenic concentrations are correlated with lower arsenic methylation capacity. This might be attributable to saturation of the arsenic metabolic pathway [48].

\section{Conclusions}

The results of this study indicate that the arsenic methylation capacity of humans exposed to arsenic in drinking water is affected by gender, age, and arsenic levels in drinking water. Urinary concentrations of iAs, MMA, DMA, and TAs were generally higher in males than in females. Females had a higher arsenic methylation capacity compared to males. Younger subjects had a lower primary arsenic methylation capacity, while the secondary arsenic methylation capacity was hardly affected by age. Moreover, exposure to higher arsenic levels in drinking water was correlated with lower primary and secondary arsenic methylation capacities.

Acknowledgments The work described in this paper was financially supported by the State Key Program of National Natural Science of China (Grant No. 41230749) and the National Public Welfare Sectors (Agriculture) special research fund (Project No. 201203012-6).

Conflict of Interest The authors declare they have no competing financial interests.

\section{References}

1. Kile M, Hoffman E, Rodrigues EG et al (2011) A pathway-based analysis of urinary arsenic metabolites and skin lesions. Am J Epidemiol 173:778-786

2. WHO (World Health Organization) (2001) Arsenic and arsenic compounds. EHC 224. International Programme on Chemical Safety, WHO, Geneva

3. IARC (International Agency for Research on Cancer) (2004) Arsenic in drinking water. IARC Monogr Eval Carcinog Risks Hum 84:39-267

4. Rahman A, Vahter M, Ekström EC et al (2007) Association of arsenic exposure during pregnancy with fetal loss and infant death: a cohort study in Bangladesh. Am J Epidemiol 165:1389-1396

5. Balakumar P, Kaur J (2009) Arsenic exposure and cardiovascular disorders: an overview. Cardiovasc Toxicol 9:169-176

6. Chung C, Hsueh Y, Bai C et al (2009) Polymorphisms in arsenic metabolism genes, urinary arsenic methylation profile and cancer. Cancer Causes Control 20:1653-1661

7. Liu SN, Zhang L, Sun QS et al (2015) The distribution in tissues and urine of arsenic metabolites after subchronic exposure to dimethylarsinic acid (DMA(V)) in rats. Biol Trace Elem Res 156: $12-21$

8. Seow WJ, Pan WC, Kile ML et al (2012) Arsenic reduction in drinking water and improvement in skin lesions: a follow-up study in Bangladesh. Environ Health Perspect 20:1733-1738

9. Bhattacharjee P, Banerjee M, Giri AK (2013) Role of genomic in stability in arsenic induced carcinogenicity: a review. Environ Int 53:29-40 
10. Li X, Li B, Xi S et al (2013) Association of urinary monomethylated arsenic concentration and risk of hypertension: a cross-sectional study from arsenic contaminated areas in northwestern China. Environ Health 12:1-10

11. Pan WC, Seow WJ, Kile ML et al (2013) Association of low to moderate levels of arsenic exposure with risk of type 2 diabetes in Bangladesh. Am J Epidemiol 178:1563-1570

12. Zhang Q, Wang D, Zheng Q et al (2014) Joint effects of urinary arsenic methylation capacity with potential modifiers on arsenicosis: across-sectional study from an endemic arsenism area in Huhhot Basin, northern China. Environ Res 132:281-289

13. WHO (2003) Arsenic in drinking-water. Background document for preparation of WHO Guidelines for Drinking-Water Quality. World Health Organization, Geneva

14. Shraim A, Sekaran NC, Anuradha CD et al (2002) Speciation of arsenic in tube-well water samples collected from West Bengal, India, by high-performance liquid chromatography-inductively coupled plasma mass spectrometry. Appl Organomet Chem 16: 202-209

15. Chen Y, Wu F, Graziano JH et al (2013) Arsenic exposure from drinking water, arsenic methylation capacity, and carotid intimamedia thickness in Bangladesh. Am J Epidemiol 178:372-381

16. Vahter M (2002) Mechanisms of arsenic biotransformation. Toxicology 181-182:211-217

17. Thomas DJ, Waters SB, Styblo M (2004) Elucidating the pathway for arsenic methylation. Toxicol Appl Pharmacol 198:319-326

18. Huang YK, Tseng CH, Huang YL et al (2007) Arsenic methylation capability and hypertension risk in subjects living in arseniasishyperendemic areas in southwestern Taiwan. Toxicol Appl Pharmacol 218:135-142

19. Hsieh RL, Huang YL, Shiue HS et al (2014) Arsenic methylation capacity and developmental delay in preschool children in Taiwan. Int J Hyg Environ Health 217:678-686

20. Sun G, Xu Y, Li X et al (2007) Urinary arsenic metabolites in children and adults exposed to arsenic in drinking water in Inner Mongolia, China. Environ Health Perspect 115:48-652

21. Huang Y, Hsueh Y, Huang Y et al (2009) Urinary arsenic methylation capability and carotid atherosclerosis risk in subjects living in arsenicosis-hyperendemic areas in southwestern Taiwan. Sci Total Environ 407:2608-2614

22. Agusa T, Trang PTK, Lan VM et al (2014) Human exposure to arsenic from drinking water in Vietnam. Sci Total Environ 488489:562-569

23. De Castro BR, Caldwell KL, Jones RL et al (2014) Dietary sources of methylated arsenic species in urine of the United States population, NHANES 2003-2010. PLoS One 9(9):1-12

24. Kitchin KT (2001) Recent advances in arsenic carcinogenesis: modes of action, animal model systems, and methylated arsenic metabolites. Toxicol Appl Pharmacol 172:249-261

25. Styblo M, Drobna Z, Jaspers I et al (2002) The role of biomethylation in toxicity and carcinogenicity of arsenic: a research update. Environ Health Perspect 110:767-771

26. Li X, Li B, Xu Y et al (2011) Arsenic methylation capacity and its correlation with skin lesions induced by contaminated drinking water consumption in residents of chronic arsenicosis area. Environ Toxicol 26:118-123

27. Xi S, Zheng Q, Zhang Q et al (2011) Metabolic profile and assessment of occupational arsenic exposure in copper and steel smelting workers in China. Int Arch Occup Environ Health 84:347-353

28. Huang YK, Huang YL, Hsueh YM et al (2008) Arsenic exposure, urinary arsenic speciation, and the incidence of urothelial carcinoma: a twelve-year follow-up study. Cancer Causes Control 19:829839
29. Steinmaus C, Yuan Y, Kalman D et al (2010) Individual differences in arsenic metabolism and lung cancer in a case-control study in Cordoba, Argentina. Toxicol Appl Pharmacol 247:138-145

30. Lindberg AL, Kumar R, Goessler W et al (2007) Metabolism of low-dose inorganic arsenic in a central European population: influence of sex and genetic polymorphisms. Environ Health Perspect 115:1081-1086

31. Yu RC, Hsu KH, Chen CJ et al (2000) Arsenic methylation capacity and skin cancer. Cancer Epidemiol Biomarkers Prev 9:1259-1262

32. Chen $\mathrm{YC}, \mathrm{Su} \mathrm{H}$, Guo YL et al (2005) Interaction between environmental tobacco smoke and arsenic methylation ability on the risk of bladder cancer. Cancer Causes Control 16:75-81

33. Steinmaus C, Bates MN, Yuan Y et al (2006) Arsenic methylation and bladder cancer risk in case-control studies in Argentina and the United States. J Occup Environ Med 48:478-488

34. Pu YS, Yang SM, Huang YK et al (2007) Urinary arsenic profile affects the risk of urothelial carcinoma even at low arsenic exposure. Toxicol Appl Pharmacol 218:99-106

35. Guo X, Fujino Y, Kaneko S et al (2001) Arsenic contamination of groundwater and prevalence of arsenical dermatosis in the Hetao plain area, Inner Mongolia, China. Mol Cell Biochem 222:137-140

36. Deng Y, Wang Y, Ma T et al (2009) Speciation and enrichment of arsenic in strongly reducing shallow aquifers at western Hetao Plain, northern China. Environ Geol 56:1467-1477

37. Gamble MV, Liu X, Ahsan H et al (2005) Folate, homocysteine, and arsenic metabolism in arsenic-exposed individuals in Bangladesh. Environ Health Perspect 113:1683-1688

38. Saoudi A, Zeghnoun A, Bidondo M et al (2012) Urinary arsenic levels in the French adult population: the French National Nutrition and Health Study, 2006-2007. Sci Total Environ 433:206-215

39. Agusa T, Kunito T, Minh TB et al (2009) Relationship of urinary arsenic metabolites to intake estimates in residents of the Red River Delta, Vietnam. Environ Pollut 157:396-403

40. Hsueh YM, Ko YF, Huang YK et al (2003) Determinants of inorganic arsenic methylation capability among residents of the Lanyang Basin, Taiwan: arsenic and selenium exposure and alcohol consumption. Toxicol Lett 137:49-63

41. Francesconi KA, Kuehnelt D (2004) Determination of arsenic species: a critical review of methods and applications, 2000-2003. Analyst 129:373-395

42. Ahsan H, Chen Y, Kibriya MG et al (2007) Arsenic metabolism, genetic susceptibility, and risk of premalignant skin lesions in Bangladesh. Cancer Epidemiol Biomarkers Prev 16:1270-1278

43. Steinmaus C, Moore LE, Shipp M et al (2007) Genetic polymorphisms in MTHFR 677 and 1298, GSTM1 and T1, and metabolism of arsenic. J Toxicol Environ Health A 70:159-170

44. Tseng CH (2007) Arsenic methylation, urinary arsenic metabolites and human diseases: current perspective. J Environ Sci Health $\mathrm{C}$ Environ Carcinog Ecotoxicol Rev 25:11-22

45. Lindberga AL, Ekstro EC, Nermell B et al (2008) Gender and age differences in the metabolism of inorganic arsenic in a highly exposed population in Bangladesh. Environ Res 106:110-120

46. $\mathrm{Fu} \mathrm{S}, \mathrm{Wu} \mathrm{J}, \mathrm{Li}$ Y et al (2014) Urinary arsenic metabolism in a Western Chinese population exposed to high-dose inorganic arsenic in drinking water: influence of ethnicity and genetic polymorphisms. Toxicol Appl Pharmacol 274:117-123

47. Xi S, Sun Q, Wang F et al (2014) The factors influencing urinary arsenic excretion and metabolism of workers in steel and iron smelting foundry. J Expo Sci Environ Epidemiol 24:36-41

48. Del Razo LM, Garca-Vargas GG, Vargas H et al (1997) Altered profile of urinary arsenic metabolites in adults with chronic arsenicism: a pilot study. Arch Toxicol 71:211-217 